\title{
PERLINDUNGAN HUKUM TERHADAP PRODUK NANOTEKNOLOGI MELALUI HUKUM PATEN
}

\author{
Endang Purwaningsih \\ Derta Rahmanto \\ Fakultas Hukum Universitas YARSI \\ Email : e.purwaningsih@yarsi.ac.id \\ dertarahmanto@yarsi.ac.id
}

\begin{abstract}
It is a fact that only few people-scientists and manufacturers-are concerned about the existence of nanotechnology, the molecular scale products, and its follow-ups to meet the patentable invention standards. This research is particularly conducted to: (1) formulate relevant legal conditions for nanotechproducts to be granted a patent, and (2) evaluate its progress and offer decision makers some recommendations on the issue. It falls into qualitative-descriptive research category, embracing sociological approach, commonly known as normative-empirical approach. This research primarily examines the promotion of legal awareness to empower communities in a sense that they are progressively aware of nanotech legal protection. The findings reveal that-up to now-the Directorate General of Intellectual Rights (Ditjen HKI) has not applied specific laws on how to formulate relevant legal conditions for nanotech-products to be granted a patent; it only applies a policy on free-of-charge patent registration proposed by universities or higher educational institutions and SMEs (small and medium enterprises) for their inventions during the period of January-September 2012. Patent application procedures for nanotech products are not different from the ones of other technological products. Ideal formulation of legal conditions for nanotech-products to be granted a patent should include clear and specific SOP for nanotech products, supported by relevant regulation, solid law enforcement, and by competent human resources. Unfortunately, Ditjen HKI and BPOM are still faced with such problems as the lack of professional nanotech experts, imbalanced producer-consumer positions, ambiguous legal status for imported nanotech products (certification is required), and poor government support. Moreover, in the legal protection aspect, some items in the to-do list still remain: the term 'particle' should be clearly defined; the standard for handling nanotech characteristics should be clearly described; the terms and conditions for legal nanotech products should be clearly explained, considering the fact that businesses-local and international-claiming to make use of the so-called nanotechnology are gaining popularity. The measures to empower nanotech community still lag behind due to the lack of relevant regulations and the lack of support from related parties, such as insufficient number of nanotech experts in various institutions and poor legal protection. MNI is determined to bring the above ideals into reality, not only at the discourse stage but also at the stage of its development and its legal protection.
\end{abstract}


Keywords : legal protection, nanotech products, patent law

\begin{abstract}
Abstrak
Karakteristik produk nano tidak hanya berukuran kecil, dan hanya masyarakat yang dekat dan peduli dengan nano serta ilmuwan dan produsen, yang memahami sifat khas produk nano dan bagaimana menjaganya sehingga memenuhi syarat patentable invention. Secara khusus penelitian ini dilakukan dengan tujuan untuk: (1) menciptakan cara dan bentuk pematenan produk nanoteknologi dan (2) membuat evaluasi dan rekomendasi kepada decision maker tentang bentuk pematenan dan upaya pemberdayaan masyarakat nano serta peningkatan technological capabilities. Penelitian ini termasuk dalam penelitian deskriptif kualitatif dengan pendekatan sosiologis, atau dalam penelitian hukum biasa disebut normatif terapan / normatif empiris. Penelitian lebih difokuskan pada implementasi legal awareness utamanya guna membentuk masyarakat yang berdaya guna secara progresif dalam upaya perlindungan hukum produk Nano. Berdasarkan hasil penelitian diketahui bahwa hingga saat ini Direktorat Jenderal Hak Kekayaan Intelektual Republik Indonesia belum menerapkan kebijakan khusus mengenai cara dan bentuk pematenan produk nanoteknologi. Ditjen HKI hanya menerapkan kebijakan pendaftaran paten secara prodeo/gratis bagi invensi yang didaftarkan oleh universitas/perguruan tinggi dan usaha kecil dan menengah (Januari September 2012). Permohonan paten atas produk nano pun tidak berbeda dengan produk teknologi lainnya. Cara dan bentuk pematenan produk nano yang tepat yakni dengan standar nano yang jelas dalam bentuk regulasi dan penegakan hukum yang kuat, didukung oleh ketersediaan SDM. Terdapat hambatan pada sumber daya manusia di Ditjen HKI dan BPOM (ketidaksiapan tenaga profesional / ahli Nano), ketidakseimbangan produsen dan konsumen, status legal dan ilegal nano dari luar negeri (perlu sertifikasi), dan dukungan pemerintah. Selain itu dalam bidang perlindungan hukum, perlu dijelaskan secara konseptual, apa batasan / definisi partikel, cara mengatasi karakterisitik Nano, syarat dan aturan produk nano yang legal, di samping maraknya bisnis yang mendaku menggunakan teknologi nano baik impor dan nano dari Indonesia sendiri. Pemberdayaan masyarakat nano belum diimbangi oleh kebijakan pemerintah dan uluran tangan pelbagai pihak yang mendukung, seperti halnya dalam rangka ketersediaan sumber daya ahli di pelbagai institusi dan upaya perlindungan hukumnya. MNI ingin melangkah tidak hanya sebatas tempat komunikasi, akan tetapi lebih ditingkatkan ranah kegiatannya khususnya dalam pengembangan nanoteknologi dan perlindungannya.
\end{abstract}

Kata Kunci : Perlindungan hukum, produk nanoteknologi, hukum paten 


\section{PENDAHULUAN}

Nanoteknologi menjadi harapan umat manusia dalam menyelesaikan berbagai permasalahan teknologi yang dihadapi saat ini. Pendapat masyarakat nano, dengan nanoteknologi, material dapat didesain sedemikian rupa dalam orde nano, sehingga sifat-sifat yang belum dikenal dapat diakses. Masyarakat awam yang belum tahu tentang nano, baik dari segi kemanfaatan sosiologis, bisnis, teknologi dan hukum, perlu membuka jendela dunia dengan hadirnya teknologi nano. Aplikasi nanoteknologi akan membuat revolusi baru dalam dunia industri, dan diyakini bahwa pemenang persaingan global di masa yang akan datang adalah negara-negara yang dapat menguasai teknologi nano dan mengintegrasikan dalam seluruh aspek ilmu pengetahuan dan teknologi di negaranya. Untuk menguasai teknologi nano, bangsa Indonesia memerlukan kerjasama berbagai pihak dan mensinergikan berbagai potensi.

Bahkan masyarakat Indonesia telah mensosialisasikan berdirinya Masyarakat Nano Indonesia (MNI) sebelumnya bernama Masyarakat Nanoteknologi Indonesia, dibentuk dengan harapan dapat menjadi forum komunikasi para peneliti dan pelaku industri, baik yang berada di pemerintahan, lembaga riset, universitas maupun dunia industri, yang tertarik atau bergerak di bidang sains dan teknologi nano. Dengan dilatarbelakangi hal tersebut di atas telah diselenggarakan Workshop Nanoteknologi yang pertama (WNT-1) pada 24 Januari 2005 di Serpong Tangerang, dilanjutkan dengan WNT-2 yang dilaksanakan pada 28 April 2005. Pada kesempatan tersebut dideklarasikan berdirinya Masyarakat Nanoteknologi Indonesia (MNI) bertempat di Kantor Lembaga Ilmu Pengetahuan Indonesia (LIPI), Jakarta

Fokus utama dari penelitian ini adalah membudayakan dan mensosialisasikan Hukum Kekayaan Intelektual (HKI) utamanya Paten (yang terangkai dalam Hak Milik Industri) dalam ranah yang lebih luas, masuk ke wilayah nanoteknologi. Selanjutnya mengupayakan model pematenan yang fix, yang diharapkan menjadi rekomendasi dari hasil penelitian ini. Harapan akan tumbuhnya kesadaran hukum dan pemberdayaan masyarakat nano terhadap perlunya Paten dalam perlindungan produk nanoteknologi, dalam dunia industri 
dan investasi, terus bergulir, guna menjamin keamanan dan perlindungan produk nanoteknologi.

Hasil karya 'mikro tekno' baik melalui R\&D masyarakat nano, sebagai peneliti atau produsen nano yang berorientasi Paten, makin mendayagunakan calon inventor ini supaya makin memaksimalkan potensi yang dimiliki, sehingga secara bersama dan berkelanjutan mampu menumbuhkan semangat inovatif dan menemukan invensi baru serta meningkatkan jumlah pendaftaran Paten. Fungsi penelitian (Research and Development) pengetahuan teknologi dan rekayasa dan kepentingan eksploitasi dalam dunia industria nano menimbulkan jaringan kerjasama antara sentra pengembangan teknologi, pusat penelitian dan pemberi jasa hukum serta pemerintah sebagai aparat legitimator hukum. Upaya pemberdayaan ketiga unsur ini sangat potensial guna meningkatkan kesadaran hukum mematenkan penemuan / produk nano dan semangat menemukan invensi baru ataupun perbaikannya (improvement and improvement on the improvement).

Selama ini implementasi legal awareness masyarakat inventor dalam upaya mendaftarkan penemuan (invensi) dan menggunakan upaya hukum guna perlindungan HKInya masih sangat rendah, bahkan mereka dengan suka rela menjual hasil intelektualitanya tanpa royalty maupun sekedar pajang nama (moral right). Para pengambil kebijakan dan putusan hukum baik di tingkat lokal maupun pusat selama ini belum mengambil kebijakan dan menuangkan dalam bentuk peraturan perundangan dengan mewadahi aspirasi dan mengangkat kepentingan masyarakat sebagai kepentingan nasional.

Masalah penting berkaitan dengan nanoteknologi adalah bahwa sejauh ini belum ada upaya yang signifikan dari masyarakat nano untuk mencari bentuk perlindungan hukum bagi produknya. Pemerintah sudah selayaknya segera memperhatikan kebutuhan masyarakat nano ini agar supaya dalam rangka industrialisasi dan investasi, produk ini akan terlindungi secara hukum. Dalam bidang hak kekayaan intelektual, maka seperti halnya hasil karya rekayasa dalam bidang mikrobiologi, tentu saja produk nano memiliki karakteristik yang berbeda daripada produk karya teknologi biasa / ukuran normal. Karakteristik produk ini tentu tidak hanya berukuran kecil, dan hanya masyarakat yang dekat dan peduli 
dengan nano serta ilmuwan dan produsen, yang memahami sifat khas produk nano dan bagaimana memeliharanya atau menjaganya sehingga memenuhi syarat patentable invention.

Penelitian ini mengkaji tentang bagaimanakah cara dan bentuk pematenan produk nanoteknologi yang tepat berdasarkan Hukum Paten; dan bagaimanakah seharusnya upaya pematenan produk Nano dan pemberdayaan masyarakat Nano dalam rangka peningkatan indigenous technological capabilities.

\section{METODE PENELITIAN}

Secara umum penelitian ini bertujuan untuk membangun budaya Paten dan kesadaran hukum mematenkan penemuan dalam bidang teknologi nano. Dampak dari penelitian ini diharapkan menghasilkan seperangkat perubahan perilaku budaya di kalangan masyarakat peminat nanoteknologi, baik hanya sebagai konsumen / peminat maupun sebagi produsen, selanjutnya masyarakat inventor dan calon inventor nano guna mendapatkan perlindungan hukum. Sebelum ke fokus tujuan khusus, terlebih dahulu peneliti mengidentifikasi dan menganalisis kebutuhan menumbuhkembangkan kesadaran hukum tentang perlunya perlindungan Paten atas produk Nano melalui pemberdayaan masyarakat nano. Penelitian ini termasuk dalam penelitian deskriptif kualitatif dengan pendekatan sosiologis, atau dalam penelitian hukum biasa disebut normatif terapan / normatif empiris.

Pada tahap awal penelitian lebih difokuskan pada implementasi legal awareness utamanya guna membentuk masyarakat yang berdaya guna secara progresif dalam upaya perlindungan produk Nano dan menciptakan cara dan bentuk pematenan yang sesuai dengan karakteristik produk Nano. Jenis data dalam penelitian ini dibagi data primer dan data sekunder. Data primer diperoleh melalui pengamatan dan wawancara, sedangkan data sekunder dipilah menjadi bahan hukum primer, bahan hukum sekunder dan bahan hukum tertier. Bahan hukum primer terdiri atas azas - azas hukum dalam HKI, bahan hukum sekunder berasal dari buku dan jurnal ilmiah serta bahan hukum tertier dari kamus dan ensiklopedia. Memahami sifat data yang dikumpulkan, maka seluruh data akan 
diolah secara kualitatif. Data primer akan ditabulasikan dan diolah secara kualitatif dan data sekunder (literatur bahan hukum) akan dianalisis secara mendalam dengan pendekatan penelitian yang telah diajukan di atas.

\section{HASIL PENELITIAN}

\section{Gambaran Umum}

Masyarakat Nano Indonesia merupakan fórum komunikasi antar para peneliti dan pelaku industri di lembaga pemerintahan, lembaga riset, universitas maupun dunia industri yang tertarik atau bergerak di bidang sains dan teknologi nano. Berdirinya MNI bertempat di Kantor LIPI pada tanggal 22 April 2009 dengan Akta Notaris I Gede Satria Budi, SH.MKn dan SK Menteri Hukum dan Hak Asasi Manusia RI nomor C-17.HT.03.01-Th 2006 tanggal 9 Mei 2009. Sejak berdiri tahun 2005 hingga saat ini MNI telah berhasil menghimpun lebih dari 150 tenaga ahli nanoteknologi di berbagai bidang, membuka jaringan ke pembuat kebijakan, Balai Riset dan perguruan tinggi di seluruh Indonesia.

Posisi strategis MNI selain berhasil menghimpun lebih dari 150 tenaga ahli dari berbagai disiplin ilmu, juga terlibat dalam pendirian ASMINOTEK (Aliansi Strategis Mikro dan Nanoteknologi) bersama dengan departemen perindustrian; MNI juga menjadi tenaga ahli dalam penyususnan stándar nanoteknologi di Indonesia bersama Badan Standarisasi Indonesia (BSN) dan MNI dipercaya menjadi wakil Indonesia dalam Asia Nano Forum (ANF).

Visi MNI adalah menjadikan Indonesia berkemampuan Iptek yang berdaya saing secara global melalui jejaring Nanoteknologi. Misinya antara lain:

1. Melakukan pelatihan, seminar, kerjasama di tingkat nasional maupun internasional dan kegiatan lain yang mendukung pengembangan nanosains dan nanoteknologi di Indonesia

2. Mengkoordinasi dan mengkomunikasi penelitian lintas institusi keilmuan dalam bidang nano sehingga terjadi sinergitas untuk memajukan iptek yang berdaya saing melalaui jejaring nano (nano-network)

3. Melakukan studi roadmap untuk penguasaan dan implementasi nanosains dan nanoteknologi, juga untuk isu - isu strategis dalam nanosains dan 
nanoteknologi, dan memberi masukan / saran kepada pemegang kepentingan terkait (nano strategy)

4. Kajian trend penelitian nano di dunia untuk menjaga kesinambungan informasi dalam hal iptek nano (nano - trend)

5. Meningkatkan sosialisasi dan membangun kesadaran akan pentingnya penguasaan nanosains dan nanoteknologi dalam skala yang lebih besar melalui diskusi dan kurikulum sekolah (nano - education).

Berdasarkan Keputusan Kepala Badan Pengkajian dan Penerapan Teknologi nomor 281/Kp/KA/XI/2002 tentang Sistem Pengelolaan HKI di lingkungan BPPT, maka Kepala Biro Umum dan Humas berhak merekomendasikan inventor, Pemulia Tanaman, Pencipta, Pendesain kepada Kepala BPPT melalui Sekretaris Utama BPPT untuk dapat dipertimbangkan diberikan penghargaan HKI sesuai ketentuan yang berlaku. Penghargaan tersebut yang karya intelektualnya dinyatakan layak untuk dimintakan perlindungan atau layak untuk dipublikasikan langsung ke industri akan diberikan insentif sesuai ketentuan yang berlaku; diberikan penghargaan dan dipublikasikan pada berbagai media informasi internal BPPT. Penghargaan kepada inventor, pemulia tanaman, pencipta, pendesain yang karya intelektualnya dinyatakan 'granted' dilindungi oleh Ditjen HKI atau Kantor PVT akan diberikan insentif sesuai peraturan yang berlaku; diberikan plakat Kepala BPPT, dipublikasikan dan diundang khusus dalam fórum apresiasi HKI oleh Kepala BPPT. Selain hal penting tersebut, royalti atau imbalan bagi hasil juga diberikan kepada inventor, pemulia tanaman, pencipta, pendisain sebesarbesarnya $40 \%$ dari hasil pemasaran HKI dengan kewajiban membayar $\mathrm{PPh}$ sesuai ketentuan yang berlaku.

Pasal 11 SK tersebut bahkan mendukung tercapainya HKI oriented, bahwa setiap usulan program kegiatan penelitian harus berorientasi pada perolehan HKI dan seyogyanya suatu usulan program kegiatan penelitian tersebut didukung dengan data hasil penelusuran HKI. 
Berdasarkan hasil wawancara dengan Fidel Kasman ${ }^{1}$ bahwa setiap unit dalam BPPT didorong untuk menghasilkan HKI setidaknya 1 per tahun, jadi hingga tahun Maret 2012 BPPT telah mengantongi 56 paten. Bagian yang perlu diperhatikan dalam pendaftaran paten adalah selain syarat novelty, inventive step, industrial applicable, juga aplikasi harus memenuhi clarity dan unity. Selain itu untuk mempercepat proses pematenan maka diaktifkanlah mediasi, yakni mempertemukan pemeriksa substantif, dan inventor. BPPT juga mewadahi invensi dari luar BPPT melalui perjanjian kerjasama untuk membuat (meneliti dan menemukan), mendaftarkan paten dan mengeksploitasi invensi tersebut, beserta kesepakatan mengenai biaya. Jika telah granted, maka HKI bisa dipasarkan oleh bagian pemasaran HKI untuk men'jual' HKI nya.

Berdasarkan hasil wawancara dengan Ratno, ${ }^{2}$ masyarakat Nano merupakan wadah sosial yang berisi peneliti, mahasiswa dan siapa saja yang berminat dengan Nano. Perlu perhatian besar dari pemerintah untuk pertumbuhan nanoteknologi di Indonesia. Selama ini MNI belum memerankan peran seperti halnya Technology Licensing Organization (di Jepang), MNI merupakan bentuk ekspresi diri dengan mengadakan sosialisasi horisontal dan vertikal, memberi edukasi dan pelatihan serta informasi mengenai nanoteknologi. Kendala yang dinilai perlu dipecahkan adalah belum 'nyambung'nya industri dan peneliti. Selain perhatian dari pemerintah, perlindungan terhadap Nano juga penting, standarisasi mutu dan prosedural dalam menuju safety juga merupakan arah yang dituju. MNI tidak merakit Nano akan tetapi membuat produk Nano.

Berdasarkan hasil wawancara dengan Nur Hendrasto, ${ }^{3}$ selain telah berdiri MNI juga telah didirikan PT Nanotech Indonesia untuk lebih mewadahi aspirasi dan perlindungan hukum bagi nano. Kegiatan yang telah dilakukan adalah berbagai pelatihan, workshop, seminar, perluasan jejaring, standarisasi produk Nano, perolehan paten (lewat institusi) dan uji produk. Pada dasarnya MNI dan PT Nanotech lebih mengutamakan orientasi bisnis daripada perolehan paten.

\footnotetext{
${ }^{1}$ Bagian Unit Pengelola HKI BPPT

${ }^{2}$ Seorang doktor Nano dan pengurus MNI

${ }^{3}$ Pengurus dan peneliti Nano
} 
Berdasarkan hasil wawancara dengan Suryandaru, ${ }^{4}$ bahwa hingga saat ini telah terbentuk komunitas Nano di kampus-kampus, terdaftar sudah 15 kampus memiliki komunitas nano. Mereka melakukan pelatihan (terakhir Maret 2012 di Puspiptek Serpong).

Berdasarkan hasil wawancara dengan Nurul Taufiqurrohman, ${ }^{5}$ terdapat hambatan pada sumber daya manusia di BPOM (ketidaksiapan tenaga profesional/ahli Nano), ketidakseimbangan produsen dan konsumen, status legal dan ilegal nano dari luar negeri (perlu sertifikasi), dan dukungan pemerintah. Selain itu dalam bidang perlindungan hukum, perlu dijelaskan secara konseptual, apa batasan / definisi partikel, cara mengatasi karakterisitik Nano, person, syarat dan aturan produk nano yang legal, di samping maraknya bisnis yang mendaku menggunakan teknologi nano baik impor dan nano dari Indonesia sendiri. Memang saat ini baru saja ditetapkan standarisasi produk Nano, akan tetapi harus didukung infrastruktur yang memadai dan SDM yang profesional. Karakteristik produk Nano tidak sama dengan mikrobiologi, akan tetapi sama dengan zat kimia umumnya. Para inventor tidak perlu menitipkan contoh sampel hasil penelitian yang dimintakan paten dan berbentuk Nano tersebut, akan tetapi inventor menyimpan dan menjaganya sendiri.

Berdasarkan penjelasan Lastami, ${ }^{6}$ bahwa sejak periode Januari 2012 hingga September 2012 pemerintah memberikan fasilitas pendaftaran paten gratis / prodeo kepada para inventor sepanjang invensi tersebut diajukan pendaftarannya oleh UKM (Usaha Kecil dan Menengah) atau Universitas (invensi dosen dan mahasiswa). Diharapkan dengan insentif ini, biaya pematenan bukan merupakan kendala dalam pertumbuhan industri dan teknologi serta bagi upaya peningkatan jumlah paten di Indonesia, yang dihasilkan oleh putra bangsa ini. Universitas/perguruan tinggi sangat diharapkan dapat membantu mendobrak jumlah paten yang ada, sehingga meningkatkan perbandingan jumlah paten di Indonesia, yang biasanya paten dari putra bangsa ini sekitar 3-7\% per tahun

\footnotetext{
${ }^{4}$ Pengurus dan peneliti MNI

${ }^{5}$ Ketua MNI dan peneliti

${ }^{6}$ Direktur Kerjasama dan Promosi Direktorat Jenderal Hak Kekayaan Intelaktual RI, penjelasan diberikan pada acara pertemuan Forum Dekan Fakultas Hukum se-Jabodetabek di Universitas YARSI tanggal 6 Juni 2012)
} 
dibandingkan paten dari luar negeri. Memang belum begitu banyak produk Nano yang dipatenkan di Indonesia, bahkan di BPPT sendiri baru terdapat 56 paten dan beberapa saja menggunakan Nano.

\section{Pemberdayaan Masyarakat Nano}

Dengan mengacu pendapat Aditya Trenggono, ${ }^{7}$ kebijakan pemerintah dalam bidang ilmu dan teknologi nano masih menempatkan bidang tersebut ke dalam kerangka kebijakan yang sudah ada. Belum ada keberanian pemerintah Indonesia untuk secara khusus membuat kebijakan mendirikan pranata institusi dan program penelitian teknologi nano. Kementerian Riset dan Teknologi mendorong riset teknologi nano dengan memasukkan ilmu dan teknologi nano pada program insentif. Di tahun 2009, program insentif menitikberatkan pada penelitian terapan. Cukup jelas bahwa di tahun 2009, penelitian ilmu dasar nano belum dijadikan prioritas. Penerapan teknologi nano di Indonesia diperkirakan masih sangat rendah karena ilmu dasarnya belum kuat dan mungkin hanya segelintir ilmuwan dan lembaga yang bisa melakukan langkah aplikasi teknologi nano. Profil BPPT belum jelas menampilkan keberpihakan mereka pada teknologi nano. Melihat struktur organisasinya, tidak ada deputi, balai pengkajian dan unit pelaksana teknis khusus teknologi nano. Kebijakan Dirjen Pendidikan Tinggi (DIKTI) untuk mendukung pendidikan ilmu dan teknologi nano juga belum jelas. Dari penelusuran website DIKTI, beberapa penelitian ilmu dan teknologi nano telah didanai oleh DIKTI. Namun, program yang dikhususkan untuk pengembangan teknologi nano belum dilakukan. Integrasi ilmu dan teknologi nano ke dalam struktur pendidikan tinggi mungkin sudah dilakukan melalui berbagai program studi yang sudah ada. Di Indonesia belum banyak lembaga publik atau privat yang fokus pada penelitian atau advokasi teknologi nano.

Jadi pemberdayaan masyarakat nano belum diimbangi oleh kebijakan pemerintah dan uluran tangan pelbagai pihak yang mendukung, seperti halnya dalam rangka ketersediaan sumber daya ahli di pelbagai institusi dan upaya perlindungan hukumnya. Sesuai visi dan misi MNI, sebagai wadah sosial biasa

${ }^{7}$ nanoclub.uns.blogspot.com diakses 20 Juni 2012 
(menurut Ratno) maka MNI ingin melangkah tidak hanya sebatas tempat komunikasi, akan tetapi lebih ditingkatkan ranah kegiatannya khususnya dalam pengembangan nanoteknologi dan perlindungannya. Idealnya MNI juga ingin mencontoh lembaga semacam TLO yakni mengubah invensi melalui lisensi menjadi royalti. Kegiatan MNI terakhir pada bulan Maret 2012 adalah menyelenggarakan lokakarya bagi komunitas MNI dan seminar tentang Nano, yang semuanya diadakan di kawasan Puspiptek Serpong.

\section{PEMBAHASAN}

\section{Cara dan Bentuk Pematenan Produk Nanoteknologi yang tepat berdasarkan}

\section{Hukum Paten}

Berdasarkan hasil penelitian diketahui bahwa material produk nano meliputi karbon, komposit, metal dan paduannya, biologi, polimer, gelas dan keramik. Dalam web nya www.nano.org.id, Aditya Trenggono telah menjelaskan bahwa dengan mengacu pada orientasi industri negara maju, Pemerintah Amerika Serikat 20 dan Uni Eropa 21 berusaha menjadi yang terdepan dalam penelitian potensi dan aplikasi ilmu dan teknologi nano serta dampaknya terhadap masyarakat dan lingkungan. Mereka merumuskan, mengkoordinasi dan mempublikasikan program-program, dan memberikan dukungan dana, sarana dan prasarana dalam rangka mendorong partisipasi aktif seluruh pihak yang berkepentingan (lembaga pemerintah, lembaga penelitian, lembaga pendidikan tinggi, industri, dan masyarakat). Untuk menjaga kepentingan politik, ekonomi dan teknologi mereka di abad globalisasi ini dan menjadi tempat terbaik bagi para ilmuwan untuk melaksanakan penelitiannya, mereka terlibat aktif menjalin kerjasama internasional. Sebagai indikator keberhasilan strategi mereka, program pendanaan penelitian dilakukan secara komprehensif (penelitian dasar, penelitian aplikatif, teknologi) dan berkelanjutan. Beberapa keluaran yang diharapkan dari kegiatan penelitian adalah publikasi ilmiah, pengajuan hak paten, dan pendirian perusahaan “start up". Uni Eropa melalui program "The seventh research framework program (FP7) 22, mendukung kegiatan penelitian (termasuk ilmu dan teknologi nano 21) yang melibatkan industri, organisasi publik (termasuk lembaga penelitian dan 
pendidikan), peneliti individu dan mitra di bagian dunia lain. Program penelitian teknologi nano meliputi kesehatan, elektronik, kimia, keamanan industri dan obat inovatif 23. Bidang-bidang kunci strategi Eropa dan rencana aksi meliputi penelitian, inovasi industri, infrastruktur, pendidikan, aspek sosial dan etik, penilaian resiko, peraturan dan kerjasama atau dialog internasional.

Melalui pendidikan dan kegiatan advokasi, Eropa berusaha memperkecil perbedaan akan kebutuhan terhadap sumber daya handal dan kesadaran masyarakat di bidang ilmu dan teknologi nano. Melalui program Erasmus Mundus 26, ilmu dan teknologi nano diperkenalkan melalui pendidikan teknologi maupun ilmu alam. Program tersebut memberikan beasiswa kepada mahasiswa / mahasiswi yang bukan warga negara anggota Uni Eropa untuk menempuh pendidikan di Eropa. Di setiap universitas terbaik di Eropa, kita akan mudah menemui program studi atau penelitian yang fokus kepada ilmu dan teknologi nano. Melalui forum maya yaitu nanoforum 27, Eropa berusaha menjembatani interaksi antara berbagai pihak dalam rangka pertukaran informasi tentang perkembangan teknologi nano. Di forum tersebut, aspek pendidikan juga dilakukan dengan menyediakan pengenalan teknologi nano dan memperbarui setiap perkembangan yang terjadi. ${ }^{8}$

Hingga saat ini Direktorat Jenderal Hak Kekayaan Intelektual Republik Indonesia belum menerapkan kebijakan khusus mengenai pematenan produk nanoteknologi. Ditjen HKI hanya menerapkan kebijakan pendaftaran paten secara prodeo / gratis bagi invensi yang didaftarkan oleh universitas / perguruan tinggi dan usaha kecil dan menengah. (Januari - September 2012). Dalam rangka persiapan pengajuan permohonan paten, sebagai peneliti harus melakukan penelusuran melalui laman Ditjen HKI, bahkan laman baru Ditjen HKI baru diresmikan pada Hari HKI ke-12 pada tahun 2012 ini. Dengan penelusuran ini seorang peneliti yang akan meneliti atau bahkan mungkin sudah menghasilkan invensi, akan mendapatkan informasi tentang teknologi terdahulu dalam bidang invensi yang sama yang memungkinkan ada kaitannya dengan invensi yang akan diajukan. Demikian pula dapat ditelusuri via internet United States Patent and

\footnotetext{
${ }^{8}$ nanoclub-uns.blogspot.com diakses 20 Juni 2012
} 
Trademark Office (USPTO), Japan Patent Office (JPO), dan European Patent Office(EPO).

Adapun permohonan paten atas produk nano pun tidak berbeda dengan produk teknologi lainnya, yakni langsung mendatangi Ditjen HKI / DJHKI atau melalui Kanwil Departemen Hukum dan Hak Asasi Manusia di seluruh Indonesia dengan tahapan : 1) Pengajuan permohonan; 2) Pemeriksaan administratif; 3) Pengumuman permohonan; 4) Pemeriksaan substantif dan 5) keputusan pemberian atau penolakan. Pengajuan permohonan sesuai dengan Undang Undang nomor 14 tahun 2001 tentang Paten) dilakukan dengan cara mengajukan surat permohonan secara tertulis dalam bahasa Indonesia kepada Ditjen HKI / DJHKI dengan menggunakan formulir permohonan paten yang memuat berkas untuk filing date sebagai berikut : 1) Tanggal, bulan, dan tahun permohonan; 2) Alamat lengkap dan alamat jelas orang yang mengajukan permohonan paten; 3) Nama lengkap dan kewarganegaraan inventor; 4) Nama lengkap dan alamat kuasa (jika permohonan paten diajukan melalui kuasa); 5) Surat kuasa khusus, dalam hal permohonan diajukan melalui kuasa; 6) Pernyataan permohonan untuk dapat diberi paten; 7) Judul invensi; 8) Klaim; 9) Deskripsi tentang invensi, yang secara lengkap memuat keterangan tentang cara melaksanakan invensi; 10) Gambar yang disebutkan dalam deskripsi yang diperlukan untuk memperjelas invensi dan 11) Abstrak invensi. Dokumen deskripsi, klaim, abstrak, dan gambar ini biasanya disebut dengan spesifikasi paten.

Jadi cara dan bentuk pematenan produk nanoteknologi selama ini tidak berbeda dengan cara dan bentuk pematenan produk lain. Berdasarkan hasil wawancara dengan Ketua MNI (pada bahasan hasil penelitian) bahwa sangat diperlukan koridor hukum yang jelas untuk memastikan apakah material yang dibuat benar-benar nanoteknologi, dan hingga saat ini pada instansi Ditjen HKI belum ada SDM yang mendukung (pada pemeriksaan substantif) sementara di BPOM (khusus pemeriksaan laik edar obat dan makanan) juga mengalami hal yang sama. Sementara ini produk yang bertebaran di pasaran dan pengusahanya mendaku menggunakan nano sangat banyak baik obat, makanan dan kosmetik, sehingga sangat mungkin mengelabui konsumen, karena tidak ada pemeriksaan 
yang jelas, meskipun baru - baru ini telah terbit stándar produk nano, akan tetapi perlu pengawasan dan penegakan hukumnya.

Seharusnya pemerintah mengkualifikasi secara jelas, produk apa saja yang secara aman dapat diberikan nanoteknologi dan penggunaannya tentu sesuai aturan stándar yang jelas, jika bersinggungan dengan obat makanan kosmetik dan lingkungan. Selain itu pemerintah harus menyiapkan pemeriksa subtsantif dan ahli nano dipergunakan di berbagai isntitusi yang relevan, seperti Ditjen HKI dan BPOM. Selain ketersediaan aturan hukum yang spesifik tentang nano dan pematenannya di Indonesia, pengawasan dan penegakan hukum, Sumber daya manusia, juga diperlukan pengembangan teknologi melalui kampus perguruan tinggi dan kerjasama nasional dan internasional, meningkatkan lembaga riset dan pengembangan bidang nanoteknologi, dan pemberdayaan masyarakat nano itu sendiri.

Upaya pematenan produk Nano dan pemberdayaan Masyarakat Nano dalam rangka peningkatan indigenous teshnological capabilities

Berdasarkan hasil penelitian diketahui terdapat hambatan pada sumber daya manusia di BPOM (ketidaksiapan tenaga profesional / ahli Nano), ketidakseimbangan produsen dan konsumen, status legal dan ilegal nano dari luar negeri (perlu sertifikasi), dan dukungan pemerintah. Selain itu dalam bidang perlindungan hukum, perlu dijelaskan secara konseptual, apa batasan / definisi partikel, cara mengatasi karakterisitik Nano, person, syarat dan aturan produk nano yang legal, di samping maraknya bisnis yang mendaku menggunakan teknologi nano baik impor dan nano dari Indonesia sendiri. Memang saat ini baru saja ditetapkan standarisasi produk Nano, akan tetapi harus didukung infrastruktur yang memadai dan SDM yang profesional. Karakteristik produk Nano tidak sama dengan mikrobiologi, akan tetapi sama dengan zat kimia umumnya. Para inventor tidak perlu menitipkan contoh sampel hasil penelitian yang dimintakan paten dan berbentuk Nano tersebut, akan tetapi inventor menyimpan dan menjaganya sendiri. Visi MNI adalah menjadikan Indonesia berkemampuan iptek berdaya saing secara global melalui jejaring teknologi nano. Lembaga ini diharapkan 
menjadi forum komunikasi berbagai pihak yang tertarik atau bergerak dalam bidang sains dan teknologi nano. Tidak mudah mencari kebijakan dan arah penelitian secara mendetail di Indonesia. LIPI dan MNI belum secara transparan menentukan arah perkembangan ilmu dan teknologi nano di Indonesia.

Jadi pemberdayaan masyarakat nano belum diimbangi oleh kebijakan pemerintah dan uluran tangan pelbagai pihak yang mendukung, seperti halnya dalam rangka ketersediaan sumber daya ahli di pelbagai institusi dan upaya perlindungan hukumnya. Sesuai visi dan misi MNI, sebagai wadah sosial maka MNI ingin melangkah tidak hanya sebatas tempat komunikasi, akan tetapi lebih ditingkatkan ranah kegiatannya khususnya dalam pengembangan nanoteknologi dan perlindungannya. Idealnya MNI juga ingin mencontoh lembaga semacam TLO yakni mengubah invensi melalui lisensi menjadi royalti. Jika digambarkan maka pola pemberdayaan yang ingin dicapai oleh masyarakat Nano Indonesia adalah sebagai berikut.

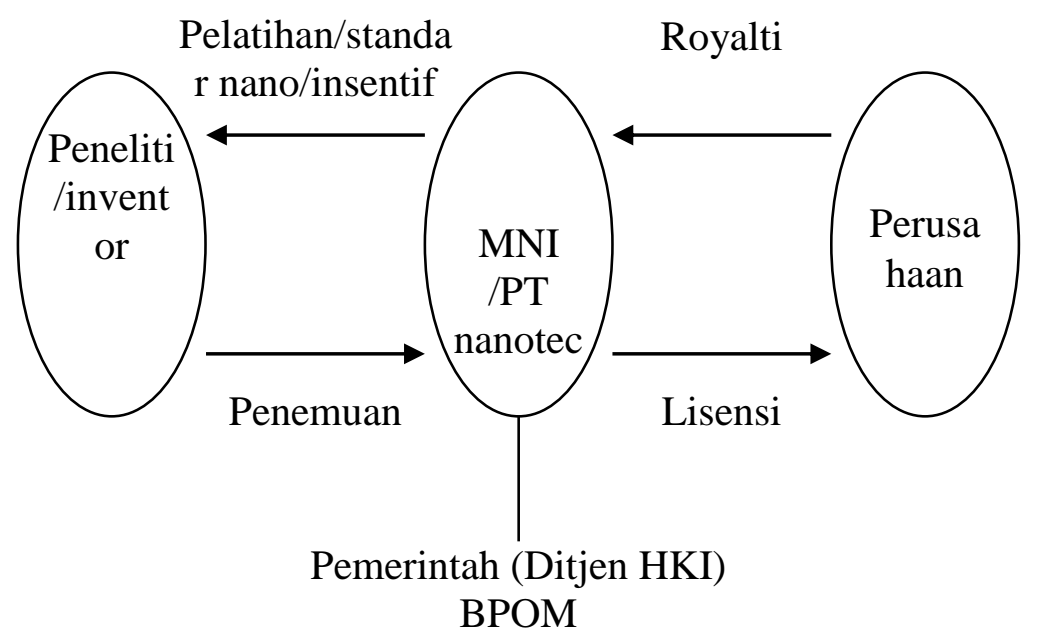

Gambar Model

Pemberdayaan 


\section{PENUTUP}

\section{Kesimpulan}

Berdasarkan uraian pembahasan di atas, dapat ditarik kesimpulan sebagai berikut.

1. Hingga saat ini Direktorat Jenderal Hak Kekayaan Intelektual Republik Indonesia belum menerapkan kebijakan khusus mengenai cara dan bentuk pematenan produk nanoteknologi. Ditjen HKI hanya menerapkan kebijakan pendaftaran paten secara prodeo / gratis bagi invensi yang didaftarkan oleh universitas/perguruan tinggi dan usaha kecil dan menengah (Januari September 2012). Dalam rangka persiapan pengajuan permohonan paten, sebagai peneliti harus melakukan penelusuran melalui laman Ditjen HKI, atau pun United States Patent and Trademark Office (USPTO), Japan Patent Office (JPO), dan European Patent Office(EPO). Permohonan paten atas produk nano pun tidak berbeda dengan produk teknologi lainnya, yakni dengan cara datang langsung ke DJHKI atau melalui Kanwil Departemen Hukum dan Hak Asasi Manusia di seluruh Indonesia dengan tahapan : 1)Pengajuan permohonan; 2) Pemeriksaan administratif; 3)Pengumuman permohonan; 4) Pemeriksaan substantive dan 5) keputusan pemberian atau penolakan. Cara dan bentuk pematenan produk nano yang tepat yakni dengan standar nano yang jelas dalam bentuk regulasi dan penegakan hukum yang kuat, didukung oleh ketersediaan SDM.

2. Terdapat hambatan pada sumber daya manusia di Ditjen HKI dan BPOM (ketidaksiapan tenaga profesional / ahli Nano), ketidakseimbangan produsen dan konsumen, status legal dan ilegal nano dari luar negeri (perlu sertifikasi), dan dukungan pemerintah. Selain itu dalam bidang perlindungan hukum, perlu dijelaskan secara konseptual, apa batasan / definisi partikel, cara mengatasi karakterisitik Nano, person, syarat dan aturan produk nano yang legal, di samping maraknya bisnis yang mendaku menggunakan teknologi nano baik impor dan nano dari Indonesia sendiri. Pemberdayaan masyarakat nano belum diimbangi oleh kebijakan pemerintah dan uluran tangan pelbagai pihak yang mendukung, seperti halnya dalam rangka ketersediaan sumber daya ahli di pelbagai institusi dan upaya perlindungan hukumnya. MNI ingin 
melangkah tidak hanya sebatas tempat komunikasi, akan tetapi lebih ditingkatkan ranah kegiatannya khususnya dalam pengembangan nanoteknologi dan perlindungannya. Idealnya MNI juga ingin mencontoh lembaga semacam TLO yakni mengubah invensi melalui lisensi menjadi royalti.

\section{Saran}

1. Seharusnya cara dan bentuk pematenan produk nanoteknologi diberikan standarisasi dan regulasi yang lebih khusus, disertai dukungan sumber daya manusia (sebagai pemeriksa substanstif) dan pengawasan serta penegakan hukum yang kuat, karena produk nano telah merambah ke masyarakat luas dalam kehidupan sehari - hari.

2. Pemberdayaan masyarakat umumnya dan pemberdayaan MNI seharusnya diimbangi regulasi dan insentif dari pemerintah, dengan karakteristik dan standar (batas ambang) yang belum jelas, akan merugikan masyarakat.

\section{DAFTAR PUSTAKA}

Amirullah M., M. Oktaufik, “Tantangan dan Peluang Teknologi Industri” dalam Jurnal Ekonomi dan Manajemen, Vol 1 No. 1 Universitas Gajayana Malang, 2000

Berita Resmi Paten, Jakarta: Dirjen Paten Depkeh, 2011

Besen and Raskin dalam Donald Marron, "Which Countries Protect Intellectual Property? The Case of Saftware Piracy," Journal Economic Inquiry, vol. 38. No.2. tahun 2000

Buku Teks Dasar Hak Milik Industri, Indonesia: Terjemahan Dirjen Paten, 2011

Cave, Davies Collision, "Right, Infringement of Rights \& Remedies," executive summary, Presentation to Indonesia Australia Specialized Training Project Intellectual Property Rights, Surabaya, 1996. 
Coombe, Rosemary J.. "The Cultural life of Intellectual Properties, Authorship, Appropriation and the Law" dalam reviewer Friedman, Jonathan. Journal American Ethnologist Vol 26 No 4 tahun 1999

Dickinson, US Patent and Trademark Office (USPTO), IP Community no.3, (APIC/JIII) , 2003

Dirjen Paten, Statistik Paten, dalam http://www.dgip.go.id

Djumhana, Muhammad dan R. Djubaidillah, Hak Milik Intelektual, Sejarah, Teori dan Prakteknya di Indonesia; Bandung: Citra Aditya Bakti, 2003

Endang Purwaningsih, Perkembangan Hukum Intellectual Property Rights, Jakarta: Ghalia Yudistira, 2005

Endang Purwaningsih, Paten sebagai Konstruksi Hukum Perlindungan invensi dalam bidang Teknologi dan Industri, Jurnal Pro Justitia,UNPAR, 2005

Endang Purwaningsih, Paten sebagai Penentu Besarnya Monopoly Patent Rights dalam Dunia Industri, Jurnal Gloria Yuris, Unika Atmajaya, 2006.

Endang Purwaningsih, Perlindungan Paten menurut Hukum Paten Indonesia, Jurnal Media HKI, ed.Jan-Feb, Ditjen HKI, 2007

Endang Purwaningsih,. Hak Kekayaan Intelektual dan Lisensi, Bandung:Mandar Maju , 2012

Endang Purwaningsih, Kapita Selekta Hukum Ekonomi, Kediri: Jenggala Pustaka Utama, 2009

Endang Purwaningsih,. Model Pengembangan Budaya Paten di Kalangan Kampus dalam rangka Menumbuhkembangkan Indigenous Technological Capabilities, Jurnal Adil, vol.1 no.1 FH Universitas YARSI, 2010

Granstrand, Ove, The Economic and Management of Intellectual Property, United Kingdom: Edward Elgar.1999

Gunawan Widjaja, Seri Hukum Bisnis Lisensi, Jakarta: PT Raja Gafindo Persada, 2001

IP Community, No.4. Trends of IP tahun 2003

International Conference papers: The Role of Law in National Development and The Future of Nanotechnology in Indonesia, UPH Jakarta, Maret 2010.

Majalah GEMA Deperind RI, Oktober 2009 
184 ADIL : Jurnal Hukum Vol. 3 No.1

Media HKI, Ditjen HKI Depkeh dan HAM, Agustus 2009

Marzuki, Peter Mahmud, 2002, "Reaglining Indonesian Law Concerning Economic Activities Under The State Guidelines of 1999”, Jurnal Yuridika FH UNAIR vol. 17 Nomor 1 tahun 2002

Undang-Undang Nomor 14 tahun 2001 tentang Paten

UU No. 18 tahun 2002, tentang Sistem Nasional Penelitian, Pengembangan dan Penerapan Ilmu Pengetahuan dan Teknologi

(www.nano.or.id) dan (www.id. Shvoong.com>Sains) 